Bull. Chem. Soc. Ethiop. 2020, 34(1), 83-92.

ISSN 1011-3924

(c) 2020 Chemical Society of Ethiopia and The Authors

Printed in Ethiopia

DOI: https://dx.doi.org/10.4314/bcse.v34i1.8

\title{
SYNTHESIS, CHARACTERIZATION AND MOLECULAR DOCKING STUDIES OF Co(II) METAL COMPLEX OF SULFATHIAZOLE
}

\author{
Otuokere Ifeanyi Edozie ${ }^{1 *}$, Ohwimu Joseph Godday ${ }^{1}$, Amadi Kingsley Chijioke ${ }^{1}$, Igwe Okenwa \\ Uchenna $^{1}$ and Nwadire Felix Chigozie ${ }^{1}$ \\ ${ }^{1}$ Department of Chemistry, Michael Okpara University of Agriculture, Umudike, P.M.B. 7267, \\ Umudike, Nigeria
}

(Received November 20, 2018; Revised November 26, 2019; Accepted December 15, 2019)

\begin{abstract}
Sulfathiazole (SFTZ) is a sulfonamide used for the treatment of bacterial infection. The cobalt complex of sulfathiazole was synthesized by reaction of sulfathiazole with $\mathrm{CoCl}_{2} \cdot 6 \mathrm{H}_{2} \mathrm{O}$. The metal complex was characterized based on AAS, UV, IR, ${ }^{1} \mathrm{H}$ NMR spectroscopy and X-ray powder diffraction. The electronic spectrum of the ligand showed intra ligand charge transfer (ILCT) which were assigned to the chromophores present in the ligand, while that of the complex suggested intra ligand charge transfer (ILCT) and ligand to metal charge transfer (LMCT). The IR spectra of the complexes showed the involvement of amine, sulfonyl and cyano group in coordination to the metal ion. This showed that sulfathiazole acted as a tridentate ligand. ${ }^{1} \mathrm{H}$ NMR spectrum of [Co(SFTZ)] complex further showed the involvement of the amine and sulfonyl group in coordination to the metal ions. The structure of $[\mathrm{Co}(\mathrm{SFTZ})]$ complex was assigned as trigonal. The crystal structure of [Co(SFTZ)] complex belongs to cubic system, space group P1, with cell parameters of $\mathrm{a}=4.007 \AA, \mathrm{b}=5.0078 \AA$, $\mathrm{c}=5.9844 \AA, V=30.61 \AA^{3}, \alpha=90^{\circ}, \beta 90^{\circ}, \gamma=90^{\circ}$. Molecular docking suggested that the ligand/complex binded effectively with the $E$. Coli and $S$. aureus because their global binding energies were negative. The binding interactions of ligand/complex with E. Coli and S. Aureus were predicted. Molecular docking predicted the feasibility of the biochemical reactions before experimental investigation.
\end{abstract}

KEY WORDS: Sulfathiazole, Synthesis, Spectroscopy, Molecular docking

\section{INTRODUCTION}

Sulfathiazole (SFTZ) and their metal complexes possess antibacterial activity, diuretic, antiglaucoma, antiepileptic, antifungal activity [1-2] and, in many cases, the activity of the metal complex is much better than the ligand alone [1-2]. Studies on their metal chelates could have much physiological and pharmacological relevance because the metal chelates of sulfadrugs have been found to be more bacteriostatic than the drugs themselves [3-4]. The role of metal ions in living systems has been well established in recent years. The use of transition metal complexes as medicinal compounds has become more and more prominent. These complexes offer a great diversity in their action; they do not only have anti-cancer properties but have also been used as anti-inflammatory [5], anti-infective [6] and anti-diabetic compounds [7].

Metal ions play pivotal roles in many biological processes, and the study of the roles of these metal ions in biological systems falls into the rapidly developing interdisciplinary field known as bioinorganic chemistry. When compared to other branches of natural sciences, bioinorganic chemistry seems to be an interesting discipline. However, there is a copious amount of information on the effects of metals on biological systems. For instance, the toxicities of metal ions such as mercury, lead and chromium on the environment have been reported [8-9]. Metal chelation is a brilliant way to increase the lipophilic character of the organic moiety. Infact, on coordination, ligands would possibly improve their bioactivity profiles whereas some inactive ligands could acquire medicinal properties and consequently they have become a very important category of structure-selective binding agents for nucleic acids [10-11].

*Corresponding author. E-mail: ifeanyiotuokere@gmail.com

This work is licensed under the Creative Commons Attribution 4.0 International License 
Various Co(III) complexes have been reported with antimicrobial activities. For instance, a Co(III) complex of the known antiulcer drug famotidine turned out to have greater antimicrobial activity against $E$. coli and $M$. lysodeikticusthan the metal free drug [12]. The pyrazine-2,3dicarboxylate complexes of 1,10-phenanthroline and alkyl diamines have recently shown activity against Gram(+) and Gram(-) bacterial strains and fungi C. albicans. The cobalt(II) complexes of hinikitiol, 4-isopropyltropolone, appeared to be active, in comparison to copper(II) complexes [13-14]

Interesting biological properties have been found in the series of metal(II) oxinates of the derivative of sulfonohydrazide, belonging to the group of sulfonamides. The octahedral cobalt complex possessed good activity against both $\operatorname{Gram}(+)$ and $\operatorname{Gram}(-)$ bacterial strains but not higher than the free ligand alone [15]. Cobalt(II) complexes not only show antimicrobial but also antifungal activities. The complex of the imidazole-2-carbaldehyde semicarbazone turned out to be active against the yeasts $S$. cerevisiae and $C$. tropicalis. Activity was most noticeable against such phyto pathogenic fungi as Alternaria or Sclerotinia. Moreover, several cobalt(II) 2methylthionicotinate complexes of various N-heterocyclic ligands showed significant activity against bacterial strains and fungi. It turned out that complexation of the nicotinate derivatives led to an elevation of their biological activity [16].

Cobalt(II) complexes of the Schiff bases had been developed for their antimicrobial and antifungal properties. Polyether ionophore antibiotics of Monensin produced by Streptomyces are biologically active compounds. The simple $\mathrm{Co}^{3+}$ ion is unstable in water, but can be stabilized against reduction to $\mathrm{Co}^{2+}$ by coordination to ligands or chelators. The chelating N,O donor ligand is by far the most common ligand type used to stabilize the cobalt(III) ion in aqueous solution. Amazingly, cobalt(III) complexes derived from this ligand donor set have found application as antibacterial or antiviral agents [15]. One of the most promising classes of Co(III) complexes containing N,O donor ligands is the 2-methylimidazole complex. In 1998, Epstein and coworkers reported that the cobalt complex of 2-methylimidazole was effective in the treatment of epithelial herpetic keratitis, one of the major causes of blindness in industrial nations [17]. Spectral characterization and antimicrobial activity of some transition metal complexes of 2-(5-nitro-1H-benzimidazol-2-yl)-4-bromophenol have been reported [18]. Synthesis, X-ray analysis and antibacterial study of silver complex with ethyl-5-hydroxy-2-oxo$2 \mathrm{H}$-chromene-3-carboxylate have also been reported [19].

We hereby report the synthesis, characterization and molecular docking studies of Cosulfathiazole complex.

\section{EXPERIMENTAL}

All chemicals and reagents used in the experimental work were of analytical grade. Melting points of the complex was determined using MPA160 melting point apparatus. Percentage of Co was determined using atomic absorption spectroscopy Duck-2010 spectrometer (Duck instrumental company) [14]. Infrared spectra were collected on Perkin Elmer Paragon 1000 FTIR spectrophotometer (spectrum BX) equipped with cesium iodide window $\left(4000-350 \mathrm{~cm}^{-1}\right.$ ) in $\mathrm{KBr}$ pellets. The UV-Visible spectra were obtained on a Perkin Elmer (lambda 25) spectrometer (200-800 nm) using DMSO as solvent. The ${ }^{1} \mathrm{H}$ nuclear magnetic resonance (NMR) spectra were obtained using Varian $400 \mathrm{MHz}$ Unity INOVA.

\section{Synthesis of sulfathiazole and its metal complex}

The complex was prepared following a reported procedure [20]. Co(II) salt solution was prepared by dissolving $4.94 \mathrm{~g}(0.02 \mathrm{~mol}) \mathrm{CoCl}_{2} \cdot 6 \mathrm{H}_{2} \mathrm{O}$ in $25 \mathrm{~mL}$ of distilled water. The solution of the metal salt was added slowly with stirring in a separate $20 \mathrm{~mL}$ of distilled water containing $5.1 \mathrm{~g}$ of sulfathiazole $(0.02 \mathrm{~mol})$ at room temperature maintaining the $\mathrm{pH}$ between $6.0-6.5$ by adding dilute solution of $\mathrm{KOH}$. The synthesis was carried out with stirring at room temperature. 
After 1 hour, the complex separated out. The complex was washed well with distilled water, recrystallized, filtered, dried in vacuum and weighed. (Yield: $85.2 \%$ ).

\section{Protein preparation}

The three-dimensional structure of Escherichia coli and Staphylococcus aureus were obtained from the Protein Data Bank, PDB 1E91 and 1STN, respectively. The protein structures were subjected to a refinement protocol using Molegro Molecular Viewer. Molecular docking was performed using Patch Dock Server: an automatic server for molecular docking [22]. Refinement was done in Fire Dock Server: An automatic server for fast interaction refinement in molecular docking and processed with Molegro molecular viewer [22-25].

\section{$X$-Ray crystal structure determination}

Appropriate amounts of the crystals were collected and deposited on Bruker D8 diffractometer operating in transmission mode using germanium monochromated $\mathrm{CuK}_{\alpha 1}$ radiation, $\lambda=1.5406$ $\AA$, linear position-sensitive detector covering $12^{\circ}$ in $2 \theta, 2 \theta$ mode range $3.5^{\circ}-70^{\circ}$, step size $0.017^{\circ}$ and $17 \mathrm{~h}$ data collection time. FOX software was used for structure determination and refinement.

$$
\mathrm{C}_{9} \mathrm{H}_{9} \mathrm{~N}_{3} \mathrm{O}_{2} \mathrm{~S}_{2}+\mathrm{Co}^{2+} \longrightarrow\left[\left(\mathrm{C}_{9} \mathrm{H}_{9} \mathrm{~N}_{3} \mathrm{O}_{2} \mathrm{~S}_{2}\right) \mathrm{Co}\right]^{2+}
$$

Scheme 1. Synthesis scheme of the metal complex.

\section{RESULTS AND DISCUSSION}

Crystallographic data and structure refinement parameters for the metal complex are given in Table 1. The indexed powdered X-ray diffraction peaks is shown in Figures 1.

Table 1. Crystal data and structure refinement for [Co(SFTZ)].

\begin{tabular}{|l|l|}
\hline Crystal data & {$[\mathrm{Co}(\mathrm{SFTZ})]$} \\
\hline Temperature $(\mathrm{K})$ & 298 \\
\hline Wavelength $(\AA)$ & 0.71073 \\
\hline Crystal system & Cubic \\
\hline Space group & $\mathrm{P} 1$ \\
\hline$a(\AA)$ & 4.0070 \\
\hline$b(\AA)$ & 5.0078 \\
\hline$c(\AA)$ & 5.9844 \\
\hline$\alpha\left(^{\circ}\right)$ & $90^{\circ}$ \\
\hline$\beta\left(^{\circ}\right)$ & $90^{\circ}$ \\
\hline$\gamma\left(^{\circ}\right)$ & $90^{\circ}$ \\
\hline${\text { Volume }\left(\AA^{3}\right)}$ & $30.61(1.0 \mathrm{~V})$ \\
\hline
\end{tabular}

The crystal structure of [Co(SFTZ)] complex belongs to cubic system, space group P1, with cell parameters of $\mathrm{a}=4.007 \AA, \mathrm{b}=5.0078 \AA, \mathrm{c}=5.9844 \AA, V=30.61 \AA^{3}, \alpha=90^{\circ}, \beta 90^{\circ}, \gamma=$ $90^{\circ}$.

The percentage of Co in the complex was $18.67 \%$. This was in agreement with the calculated value of $18.81 \%$. This showed that the experimental values are in agreement with the calculated values. The purple colour of [Co(SFTZ)] suggested the formation of complex because transition metal complexes are coloured. The change in melting point from $203{ }^{\circ} \mathrm{C}$ (SFTZ) to $235^{\circ} \mathrm{C}$ [Co(SFTZ)] also indicated the formation of a new complex. 


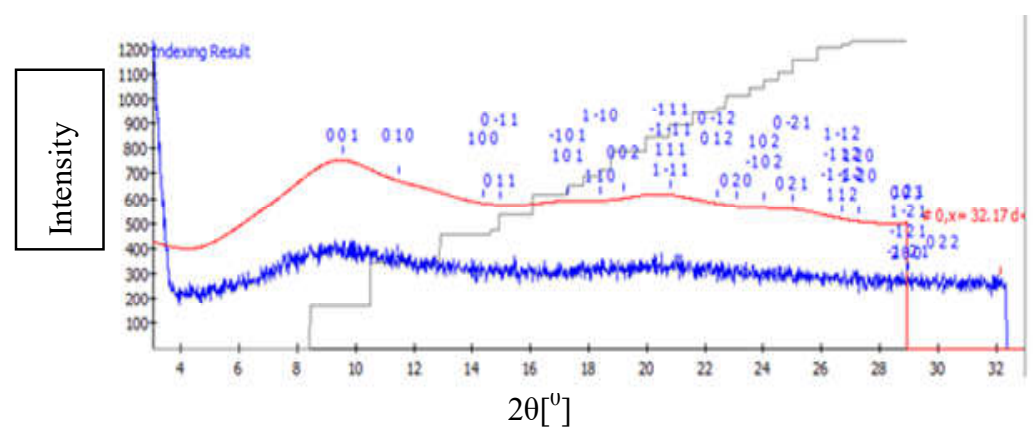

Figure 1. Indexed powdered X-ray diffraction peak for [Co(SFTZ)].
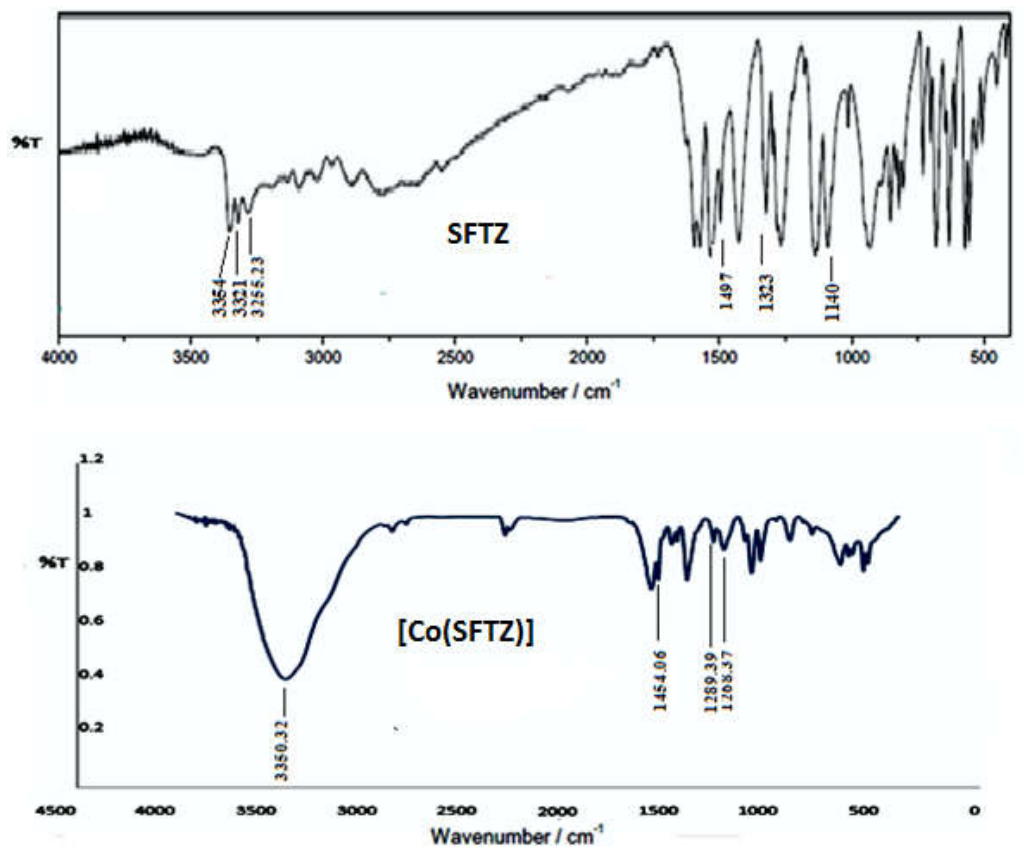

Figure 2. Infrared spectra of sulfathiazole and its $\mathrm{Co}(\mathrm{II})$ complex.

A comparison of IR spectra of SFTZ [21] and [Co(SFTZ)] complex was made (Figure 2). The infrared spectrum of SFTZ showed a broad band at 3354.00 and $3321.00 \mathrm{~cm}^{-1}$. This band was assigned N-H stretch of the primary amine due to asymmetric and symmetric stretching vibrations of the two N-H bonds. In the IR spectrum of the metal complex, this vibration frequency remained unchanged. This suggested that $\mathrm{NH}_{2}$ was not involved in complexation. Vibration frequencies at $1323.00 \mathrm{~cm}^{-1}$ and $1140.00 \mathrm{~cm}^{-1}$ were assigned to be $v_{\text {as }}(\mathrm{O}=\mathrm{S}=\mathrm{O})$ and $v_{\mathrm{S}}(\mathrm{O}=\mathrm{S}=\mathrm{O})$ in SFTZ. In the complex, these frequencies appeared at $1268.37,1128.39 \mathrm{~cm}^{-1}$ [Co(SFTZ)]. The shift to lower wave number in the IR spectrum of the complex when compared to the ligand suggested that complexation occurred through $\mathrm{O}=\mathrm{S}=\mathrm{O}$ to the $\mathrm{Co}$ ion because increase in electron density increased the $\mathrm{O}=\mathrm{S}=\mathrm{O}$ bond length and consequently slowed down 
the vibration frequency [26]. It is evident that sulfonyl group was involved in coordination to Co. In SFTZ spectrum, C-N stretching vibration was observed at $1497.00 \mathrm{~cm}^{-1}$. In the IR spectrum of the complex, this functional group was observed at $1454.06 \mathrm{~cm}^{-1}$. This observation also suggested coordination through $\mathrm{C}-\mathrm{N}$ moiety. This is because increase in electron density increased the $\mathrm{C}-\mathrm{N}$ bond length and consequently slowed down the vibration frequency. The $\mathrm{N}-\mathrm{H}$ stretch of $\mathrm{SO}_{2} \mathrm{NH}$ appeared at $3255.23 \mathrm{~cm}^{-1}$ in the free ligand. In the IR spectrum of the metal complex this band was absent. This suggested the deprotonation of the $\mathrm{N}-\mathrm{H}$ of $\mathrm{SO}_{2} \mathrm{NH}$ during complexation reaction.
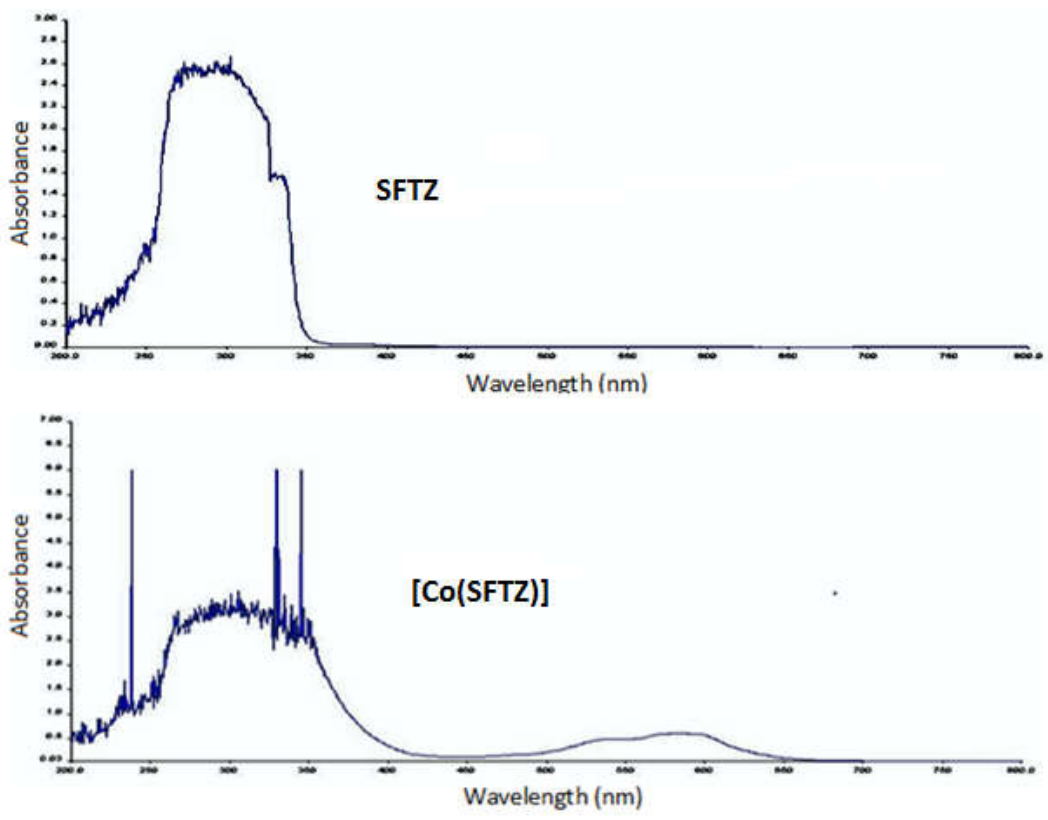

Figure 3. UV-Vis spectra of sulfathiazole and its Co(II) complex.

The UV/visible spectrum of sulfathiazole and $[\mathrm{Co}(\mathrm{SFTZ})]$ are presented in Figure 3. The UV-Vis spectrum of SFTZ showed a band centered at $269 \mathrm{~nm}$. It was assigned $\pi-\pi^{*}$ due to intraligand charge transfer (ILCT). The UV-Vis spectrum of [Co(SFTZ)] showed a band at $269 \mathrm{~nm}$ which was assigned to be $\pi-\pi^{*}$ due to intra-ligand charge transfer (ILCT). The sharp band centered at $350 \mathrm{~nm}$ was assigned to be ligand to metal charge transfer (LMCT). The broad band at $600 \mathrm{~nm}$ was due to d-d transition which suggested that complexation occurred.

The ${ }^{1} \mathrm{H}-\mathrm{NMR}$ spectra of SFTZ [21] and [Co(SFTZ)] are presented in Figure 4. In the ${ }^{1} \mathrm{H}$ NMR spectrum of SFTZ [21] (Figure 4), the aromatic protons appeared at 6.51-7.43 ppm while the thiazole protons are observed between $6.71-7.18 \mathrm{ppm} . \mathrm{NH}_{2}$ protons were observed at 5.80 ppm. In the spectrum of the $[\mathrm{Co}(\mathrm{SFTZ})]$ complex (Figure 4), these chemical shifts were unchanged. In the ${ }^{1} \mathrm{H}$ NMR spectrum of SFTZ, the hydrogen that appeared as a singlet at 12.4 ppm is no longer observed in the spectrum of the $[\mathrm{Co}(\mathrm{SFTZ})]$ complex. This was attributed to the loss of hydrogen atom of the $\left(\mathrm{O}_{2} \mathrm{~S}-\mathrm{N}-\mathrm{H}\right)$ group of SFTZ when coordination occurred through the nitrogen to the metal centre. 
Otuokere Ifeanyi Edozie et al.
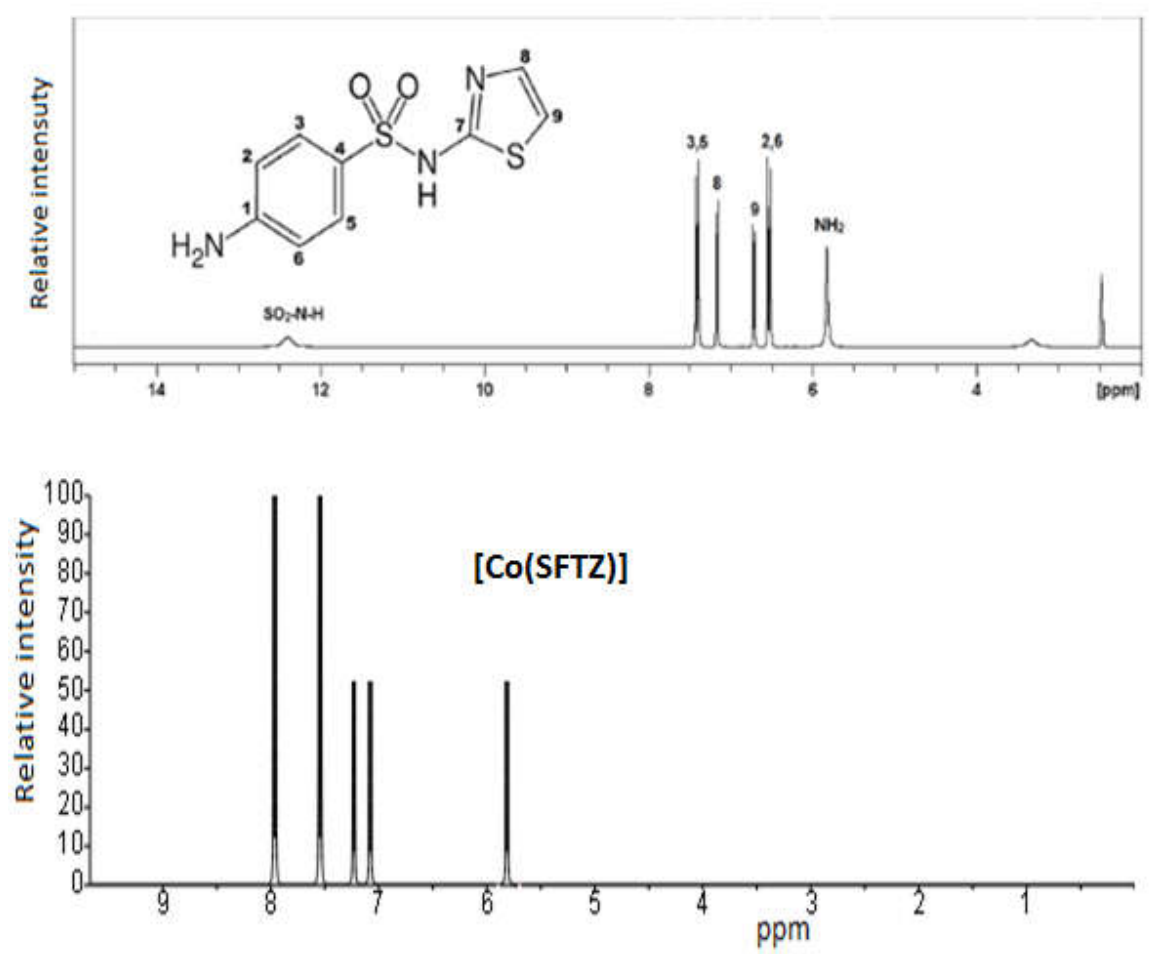

Figure 4. ${ }^{1} \mathrm{H}$ NMR spectra of sulfathiazole and its $\mathrm{Co}(\mathrm{II})$ complex.

Based on the UV, IR, ${ }^{1} \mathrm{H}$ NMR spectra and X-ray powder diffraction, a trigonal structure have been proposed for [Co(SFTZ)] (Figure 5). Cobalt complexes have been known to exhibit trigonal geometry [27-28].

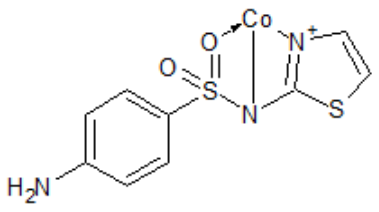

Figure 5. Proposed structure of sulfathiazole cobalt complex.

The crystal structure of E. coli contains four protein chains (A, B, C and D) and 506 water molecules. The crystal structure of $S$. aureus nuclease is made up of one protein chain (A) and 83 water molecules. The molecular docking and molecular interactions of sulfathiazole and [Co(SFTZ)] complex with E. coli and S. aureus are presented in Figures 6-9, respectively. 


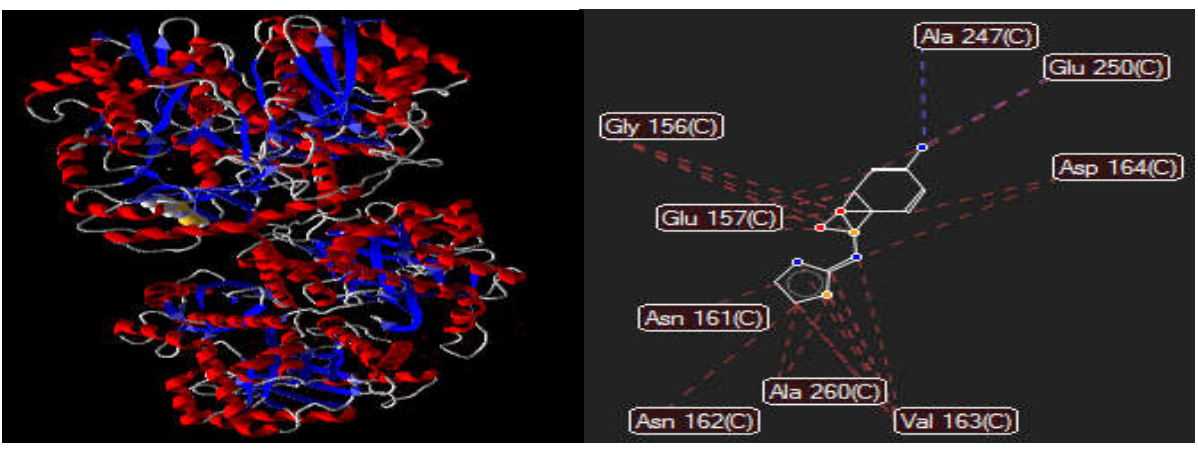

Figure 6. Molecular docking and molecular interactions of sulfathiazole with E. coli. (Binding energy $-46.74 \mathrm{kcal} / \mathrm{mol})$.

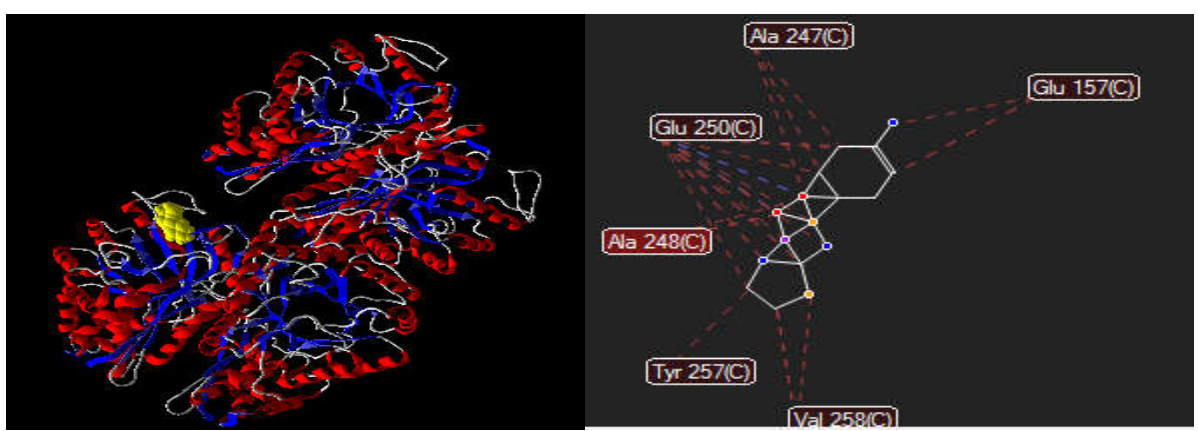

Figure 7. Molecular docking and molecular interactions of [Co(SFTZ)] complex with E. coli . (Binding energy $-38.52 \mathrm{kcal} / \mathrm{mol}$ ).

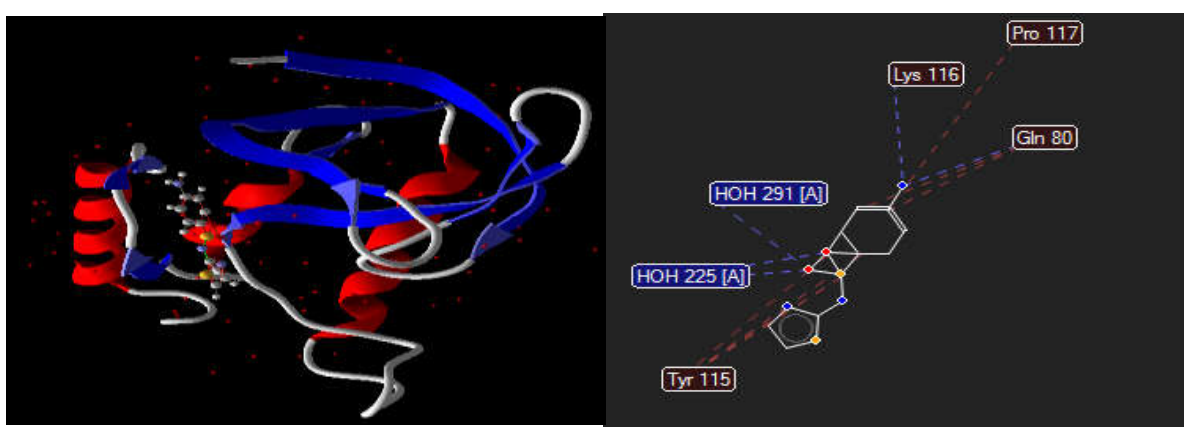

Figure 8. The molecular docking and molecular interactions of sulfathiazole with $S$. aureus. (Binding energy $-25.35 \mathrm{kcal} / \mathrm{mol}$ ). 


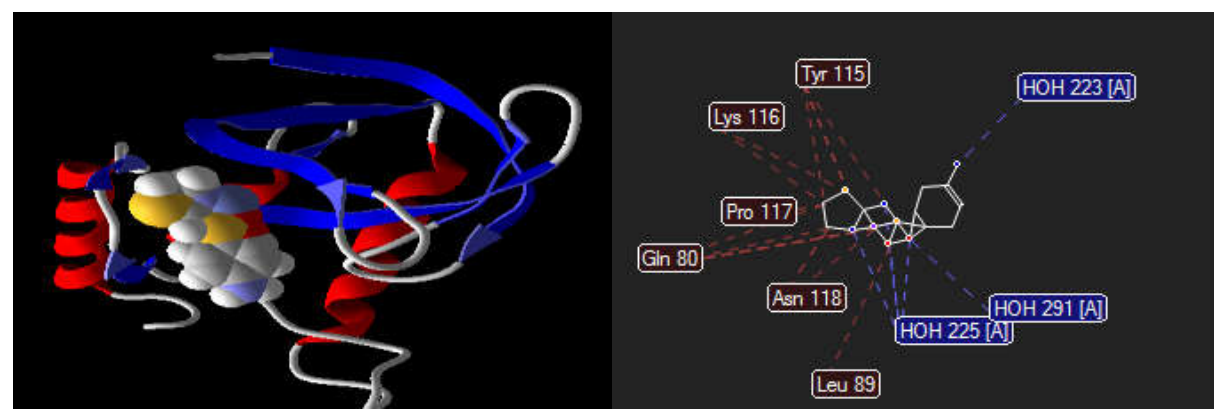

Figure 9. The molecular docking and molecular interactions of [Co(SFTZ)] complex with $S$. aureus. (Binding energy $-26.59 \mathrm{kcal} / \mathrm{mol}$ ).

The best global energy in Figure 6 is $-46.74 \mathrm{kcal} / \mathrm{mol}$. This suggested that sulfathiazole had the ability to inhibit $E$. coli. The attractive Van der Waals and atomic contact energy (ACE) showed negative values. These suggested that sulfathiazole docked effectively with $E$. coli. The molecular interactions (Figure 6) showed that E. coli formed hydrogen bonding with sulfathiazole using Ala 247 (C) and Glu 250 (C). Steric interaction between E. coli and sulfathiazole were observed with Gly 156 (C), Glu 157 (C), Asn 161 (C), Ala 260 (C), Asn 162 (C), Val 163 (C), and Asp 164 (C). The best global energy in Figure 7 is $-38.52 \mathrm{kcal} / \mathrm{mol}$. This suggested that $[\mathrm{Co}(\mathrm{SFTZ})]$ had the ability to inhibit E. coli. The attractive Van der Waals and atomic contact energy (ACE) were also predicted. Their negative values predicted effective binding. The molecular interactions (Figure 7) showed that E. coli formed hydrogen bonding with [Co(SFTZ)] via Glu 250 (C). Steric interactions between [Co(SFTZ)] and E. coli occured with Ala 247 (C), Tyr 257 (C), Val 258 (C), Ala 248 (C) and Glu 157 (C). The best global energy in Figure 8 is $-25.35 \mathrm{kcal} / \mathrm{mol}$. This suggested that sulfathiazole had the ability to inhibit $S$. aureus. The attractive Van der Waals and atomic contact energy (ACE) showed negative values. These suggested that sulfathiazole docked effectively with $S$. aureus. The molecular interactions (Figure 8) showed that $S$. aureus formed hydrogen bonding with sulfathiazole using $\mathrm{HOH} 225$ (A) and $\mathrm{HOH} 291$ (A). Steric interaction between S. aureusand sulfathiazole were observed with Gln 80, Lys 116, Tyr 115 and Pro 117. The best global energy in Figure 9 is $-26.59 \mathrm{kcal} / \mathrm{mol}$. This suggested that $[\mathrm{Co}(\mathrm{SFTZ})]$ had the ability to inhibit $S$. aureus. The attractive Van der Waals and atomic contact energy (ACE) showed negative values. These suggested that $[\mathrm{Co}(\mathrm{SFTZ})]$ docked effectively with $S$. aureus. The molecular interactions (Figure 9) showed that $S$. aureus formed hydrogen bonding with [Co(SFTZ)] using $\mathrm{HOH} 223$ (A), HOH 225 (A) and $\mathrm{HOH} 291$ (A). Steric interaction between S. aureus and [Co(SFTZ)] were observed with Lys 116, Tyr 115, Pro 117, Gln 80, Asn 118 and Leu 89.

\section{CONCLUSION}

The ability of sulfathiazole to sequestrate Co(II) has been assured. Sulfathiazole can be used to extract $\mathrm{Co}(\mathrm{II})$ from solution. Molecular docking also suggest that [Co(SFTZ)] complex will be a good inhibitor of E. coli and S. aureus. 


\section{REFERENCES}

1. Corradi, A.B.; Gozzoli, E.; Menabue, L.; Saladini, M.; Battaglia, L.P.; Sgarabotto, P. Palladium(II) complexes of N-sulfonylamino acids. Part 1. Solid-state behaviour of binary andternary 2,2'-bipyridine-containing systems. J. Chem. Soc., Dalton Trans. 1994, 273-278.

2. Drebushchak, T.N.; Boldyreva, E.V.; Mikhailenko, M.A. Crystal structures of sulfathiazolepolymorphs in the temperature range 100-295 K: A comparative analysis. $J$. Struct. Chem. 2008, 49, 84-94.

3. Casanova, J.; Alzuet, G.; Ferrer, S.; Borrás, J.; García-Granda, S.; Perez-Carreño, E. Synthesis and characterisation of cobalt complex of sulfathiazole with acetic acid. J. Inorg. Biochem. 1993, 51, 689-699.

4. Blasco, F.; Perelló, L.; Latorre, J.; Borrás, J.; Garciá-Granda, S. Cobalt(II), nickel(II), and copper(II) complexesofsulfanilamide derivatives: Synthesis, spectroscopic studies, and antibacterialactivity. Crystal structure of $\left[\mathrm{Co}(\text { sulfacetamide })_{2}(\mathrm{NCS})_{2}\right]$. J. Inorg. Biochem. 1996, 61, 143-154.

5. Shraddha, S.; Mishra, A.P. Metal complexes used as anti-inflammatory agents: Synthesis, characterization and anti-inflammatory action of VO(II)-complexes. Arab. J. Chem. 2019, $12,1715-1721$.

6. Warra, A.A.Transition metal complexes and their application in drugs and cosmetics - A Review. J. Chem. Pharm. 2011, 3, 951-958.

7. Levina, A.; Lay, P.A. Metal-based anti-diabetic drugs: advances and challenges. Dalton Trans. 2011, 40, 11675-11686.

8. Tchounwou, P.B.; Yedjou, C.G.; Patlolla, A.K; Sutton D.J. Heavy metal toxicity and the environment. Exp. Suppl. 2012, 101:133-164.

9. Silva, J.J.; Williams, R.J. The Biological Chemistry of the Elements, The Inorganic Chemistry of Life, 2nd ed. Oxford University Press: Oxford; 2001; p 20.

10. Li, A.; Liu, Y.H.; Yuan, L.Z.; Zhao, C.L. Association of structural modifications withbioactivity in three new copper(II) complexes of Schiff base ligands derived from 5chlorosalicylaldehyde and amino acids. J. Inorg. Biochem. 2015, 146, 52-60.

11. Luft, J.R; Arakali, S.V; Kirisits, J.A. Macromolecular crystallization procedure employingdiffusion cells of varying depths as reservoirs to taylor the time course of equilibration in hanging drop and sitting drop vapourdiffusion and microdialysis experiments. J. Appl. Crystallogr. 27, 1994. 443-453.

12. Miodragovic, D.U.; Bogdanovic, G.A.; Miodragovic, Z.M.; Radulovic, M.D.; Novakovic, S.B.; Kaluderovic, G.N.; Kozlowski, H. Interesting coordination abilities of antiulcer drugfamotidine and antimicrobial activity of drug and its cobalt(III) complex. J. Inorg. Biochem. 2006, 100, 1568-1574.

13. Yesilel, O.Z.; Mutlu, A.; Darcan, C.; Buyukgungor, O. Syntheses, structural characterization and antimicrobial activities of novel cobalt-pyrazine-2,3-dicarboxylate complexes with Ndonor ligands. J. Mol. Struct. 2010, 964, 39-46.

14. Nomiya K.; Yoshizawa, A.; Tsukagoshi, K.; Kasuga, N.C.; Hirakawa, S.; Watanabe, J. Synthesis and structural characterization of silver(I), aluminium(III) and cobalt(II) complexes with 4-isopropyltropolone(hinokitiol) showing noteworthy biological activities. Action of silver(I)-oxygen bonding complexes on theantimicrobial activities. J. Inorg. Biochem. 2004, 98, 46-60.

15. Segl'a, P.; Miklovic, J.; Miklos, D.; Titis, J.; Herchel, R.; Moncol, J.; Kalinakova, B.; Hudecova, D.; Mrazova, V.; Lis, T.; Melnik, M. (2008). Crystal structure, spectroscopicand magnetic properties, and antimicrobial activitiesofcobalt(II) 2-methylthionicotinate complexes with heterocyclic ligands. Transit. Met. Chem. 2008, 33, 967-974. 
16. Dixit, R.B.; Vanparia, S.F.; Patel, T.S.; Chandresh, L.J.; Doshi, H.V.; Dixit, B.C. Synthesis andantimicrobial activities of sulfonohydrazide-substituted hydroxyquinoline derivative anditsoxinates. Appl. Org. Chem. 2010, 24, 408-413.

17. Asbell, P.A.; Epstein, S.P.; Wallace, J.A.; Epstein, D.; Stewart, C.C.; Burger, R.M. Efficacy of cobalt chelates in the rabbit eye model for epithelial herpetic keratitis. Cornea 1998, 17, 550-557.

18. Aydin, T.; Mayram, H.; Demet, G.; Adem, C.; Oksüzömer, M.A.F. Spectral characterization and antimicrobial activity of some transition metal complexes of 2-(5-nitro- $1 \mathrm{H}$ benzimidazol-2-yl)-4-bromophenol. Bull. Chem. Soc. Ethiop. 2019, 33, 451-466.

19. Hajira, R.; Zulfiqar, A.; Tanzeela, G.S.; Abid, M.A.; Shahid, N.; Habib, H.; Asmat, Z.; Imdad, H. Synthesis, X-ray analysis and antibacterial study of silver complex with ethyl-5hydroxy-2-oxo-2H-chromene-3-carboxylate. Bull. Chem. Soc. Ethiop. 2019, 33, 467-474.

20. Jeffery, G.H.; Bassett, J.; Mendham, J.; Denney, R.C. Vogels Textbook of Quantitative Chemical Analysis, 5th ed., Pearson Education Publisher: Singapore; 1989; pp 473-478.

21. Julia, H.; Bormio, N.; Raphael, E.F.P.; Alexandre, C.; Wilton, R.L.; Pedro, P.C. Silver complexes with sulfathiazole and sulfamethoxazole: Synthesis, spectroscopic characterization, crystal structure and antibacterial assays. Polyhedron 2015, 85, 437-444.

22. Knegtel, R.M.A.; Kuntz, I.D.; Oshiro, C.M. Molecular docking to ensembles of protein structures. J. Mol. Biol. 1997, 266, 424-440.

23. Ikpeazu, O.V.; Igwe, K.K.; Otuokere, I.E. In silico structure-activity relationship and virtual screening of monosubstituted doxycycline with Pseudomonas aeruginosa Lipase. J. Anal. Pharm. Res. 2017, 5, 139-143.

24. Andrusier, N.; Nussinov, R.; Wolfson, H.J. FireDock Fast interaction refinement inmolecular docking. Proteins 2007, 69, 139-159.

25. Mashiach, E.; Schneidman-Duhovny, D.; Andrusier, N.; Nussinov, R.; Wolfson, H.J. FireDock: A web server for fast interaction refinement in molecular docking. Nucleic Acids Res. 2008, 36, 29-32.

26. Zacharias, M. Accounting for conformational changes during protein-protein docking CurrOpinStruct. Biol. 2010, 20, 180-186.

27. Odiaka, T.I. Modern Organometallic Chemistry, 1st ed., University Press PLC: Ibadan, Nigeria; 2004; $p 18$.

28. Alexander, A.P.; Dmitry, T.A.; Svetlana, A.S. A trigonal prismatic cobalt(II) complex as a single molecule magnet with a reduced contribution from quantum tunnelling. ChemPhysChem 2019, 20, 1001-1005

29. Alexander, A.P.; Svetlana, A.S.; Alexander, S.B. Trigonal prismatic tris-pyridineoximate transition metal complexes: A cobalt(II) compound with high magnetic anisotropy. Inorg. Chem. 2017, 56, 6943-6951. 